\title{
RETRACTED ARTICLE: An approach to evaluate the effects of virtual topology on in-band crosstalk attack propagation in transparent optical networks
}

\author{
Yonghua Xiao • Yunfeng Peng • Zeyu Sun • \\ Changming Zhao • Keping Long
}

Received: 28 August 2011 / Accepted: 15 December 2011 / Published online: 10 January 2012

(C) Springer Science+Business Media, LLC 2012

This paper has been retracted because it is copied, in parts, from the publication of another author without permission or justification.

Y. Xiao $\cdot$ C. Zhao $\cdot$ K. Long

Key Laboratory of Optical Fiber Sensing and Communications Education Ministry of China, University of Electronic Science and Technology of China, Chengdu, China

\section{Y. Peng $(\bowtie) \cdot K$. Long}

Institute of Advanced Network Technology and New Services (ANTS), School of Computer and Communication Engineering (CCE), University of Science and Technology Beijing (USTB),

Beijing 100083, China

e-mail: pengyf@ustb.edu.cn

\section{Z. Sun}

College of Communication and Information Engineering, Chongqing

University of Posts and Telecommunications, Chongqing, China 